\title{
ЛИЧНОСТНЫЙ РОСТ
}

\author{
О.А. Толмачева
}

\section{ПРОБЛЕМА ЛИЧНОСТНОЙ \\ ЗРЕЛОСТИ И САМОАКТУАЛИЗАЦИИ: ГУМАНИСТИЧЕСКИЙ ВЗГЛЯД}

\begin{abstract}
Аннотация. Предметом исследования в данной статье являются взгляды гуманистически ориентированных авторов на проблему личностной зрелости и самоактуализации. Самоактуализация - это полное раскрытие и применение потенциала личности. В каждом заложены потенциальные возможности для роста и совершенствования. Это является врождённой потребностью личности и возможно только при условии ее зрелости и тенденции к росту. Люди от рождения обладают огромными потенциями, которые угасают в результате окультуривания. Так считал создатель теории самоактуализации Абрахам Маслоу. Психологи гуманистического направления и ряд российских авторов рассматривают мотив самоактуализации как основную движущую силу в процессе развития личности. Сам мотив самоактуализации свидетельствует о личностной зрелости. Теоретико-методологической основой работы послужили: гуманистические концепции самореализации личности (А. Маслоу, К. Роджерс и др.), концепции личностного саморазвития (Б.Г. Ананьев, К.А. Абульханова-Славская, А.Г. Асмолов), а также научные представления о побуждающей и направляющей роли мотивов (Е.П. Ильин). В данной работе личностная зрелость и тенденция к самоактуализации рассматривается с точки зрения психологического здоровья личности. В этом состоит новизна исследования. Кроме того, в статье собраны основные и ведущие концепции личностного саморазвития как российских, так и иностранных авторов, где сняты противоречия во взглядах на самоактуализацию и показано, что зрелая личность - психологически здоровая личность с развитым интеллектом, умеющая реализовывать свои цели. Все это возможно только при наличии личностного здоровья. Личностное здоровье - состояние личности, обеспечивающее ее устойчивое развитие, успешный личностный рост, движение в сторону самоактуализации. Мотивационный статус здорового человека состоит, прежде всего, в стремлении к самоактуализации, понимаемой как свершение своей миссии, постижение призвания, судьбы. Самоактуализация предполагает выход глубинной природы человека на поверхность, примирение с внутренней самостью, сердцевиной личности, ее максимальное самовыражение, т.е. реализацию скрытых способностей и потенциальных возможностей, «идеальное функционирование». Таким образом, чувство индивидуальности, успешная карьера и приверженность ценностной системе также важны для психического здоровья индивида, как и безопасность, любовь, самоуважение и т.д. Если индивид стремится к удовлетворению потребностей высокого уровня, это является показателем его психического здоровья. Маслоу считает, что, удовлетворяя потребности высокого порядка, человек чувствует себя более счастливым и сама метамотивация свидетельствует о личностной зрелости. Большинство авторов рассматривают личностный рост как необходимую составляющую на пути к самоактуализации.

Ключевые слова: самоактуализация, самореализация, развитие личности, личностная зрелость, личностный рост, метапотребности, потенциал личности, мотивация, метамотивация, ценностная система.

Review. In this article the research subject is the views of humanistic philosophers and psychologists on personal maturity and personal self-fulfillment. Self-fulfilment is defined as a full release and realization of personal potential. Each person has potentials to grow and self-improve. This is an inborn need of personality and can be satisfied only when a person is mature and has a tendency to personal growth. At birth all people have huge potentials that, however, fade away as a result of the influence of culture. This is what the founder of the self-actualization theory Abraham Maslow stated. Humanistic psychologists and a number of Russian researchers view the motive for self-actualization as the main driver of personal development. The fact that a person has the motive for self-actualization proves this is a mature personality. Theoretical and methodological grounds of the research included: humanistic theory of personal self-actualization (Abraham Maslow, Carl Rogers and others), theory of personal self-development (Boris Ananiev, Ksenia Abulkhanova-
\end{abstract}




\section{Личностный рост}

Slavskaya and Alexander Asmolov) and scientific provisions about the stimulating and directing role of motives (E. Ilyin). In the present research personal maturity and tendency to self-actualization are being viewed from the point of view of the psychological health. This is what makes the novelty of the research. Moreover, the author of the article describes the basic and leading concepts of personal self-development offered by both Russian and foreign researhers that overcome contradictory views on self-actualization and demonstrate that mature personality is a psychologically healthy personality with developed intellect that knows how to achieve his or her goals. All this is possible only when there is personal health. Personal health is defined as the state of personality that ensures sustainable development, successful personal growth and movement towards self-actualization. Motivational status of a health person consists of the pursuance of self-actualization which is understood as the completion of one's mission or achievement of one's vocation or destiny. Self-actualization means the outcome of the deep nature of human to the surface, reconciliation with the inner self and personality core, maximum self-expression, i.e. realization of the hidden abilities and potentials, 'ideal performance'. Thus, the feeling of individuality, successful career and commitment to one's personal value system are as important for the psychological health of an individual as security, love, self-respect, etc. The fact that an individual aspires to fulfil his needs of the highest level is an indicator of his mental health. According to Maslow, satisfaction of the needs of the highest order allows a person to feel happier. Metamotivation itself denotes one's personal maturity. The majority of researchers view personal growth as an essential element of the path towards self-actualization.

Keywords: personal potential, meta-needs, personal growth, personal maturity, personality development, self-fulfillment, self-actualization, motivation, metamotivation, value systems.

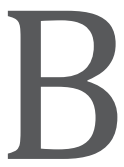

настоящее время к человеку предъявляется всё больше требований. Конкуренция на рынке труда, трудности в социальной и индивидуально-личностной коммуникации, экология и нестабильность внешней и внутренней ситуации в обществе, общая стрессогенность жизни мешают человеку функционировать в полную силу. Для здорового функционирования личности важно всё. Чувство индивидуальности, успешная карьера и приверженность ценностной системе также важны для психического здоровья индивида, как и безопасность, любовь и самоуважение. Для этого человек должен быть мотивирован чем-то большим, чем простое движение к положительному стимулу.

Лейтмотивом всей жизни для человека является его самоусовершенствование. Это врождённая потребность. В каждом из нас заложены потенциальные возможности для роста и совершенствования. Все люди от рождения обладают неограниченным потенциалом. Но не всегда и далеко не всем удаётся его реализовать.

В чём причина? Почему заданные от природы возможности и способности остаются не раскрытыми? Как получается, что врождённая потребность остаётся не актуализированной, и какое влияние на личность оказывает подобное неудовлетворение потребностей?

На эти вопросы пытались ответить отечественные и зарубежные исследователи психологии личности. В настоящей статье мы приводим основные и наиболее известные концепции и теории по данной проблеме.
Основоположники гуманистической парадигмы в науке Карл Роджерс и Абрахам Маслоу говорят о том, что человеку присуща некая внутренняя сила - тенденция к самоактуализации, направляющая его развитие в сторону наиболее полного раскрытия, разворачивания заложенных в нем возможностей, сил и способностей. В этом подходе человеку приписывается некая заданная природа, позитивная по своей сути, которая актуализируется в процессе развития. Развитие есть разворачивание того, что в человеке заложено генотипически.

К. Роджерс приписывал определение направленности развития биологической природе человека, содержащей определённый набор возможностей. И то, что человек приобретает в ходе социализации, по его мнению, влияет на проявление истинной природы.

Одна из основных задач современной психологической науки состоит в изучении личности, активно реализующей свой потенциал. В структуре её потребностей самоактуализация, как считает А. Маслоу, - самая важная потребность.

Остановимся подробнее на научных взглядах Абрахама Маслоу. Его интерес к психологии начался с увлечения теориями Дж. Уотсона, и это побудило его начать обучение бихевиористским методам. Однако его собственные исследования и наблюдения в университете Висконсина оказались любопытны в изучении социального поведения, развития чувства собственного достоинства и сопричастности и в изучении мотивации человека. 


\section{Психология и психотехника 6(81) • 2015}

\begin{abstract}
А. Маслоу определял понятие самоактуализации как «полное применение талантов, способностей, потенциалов и т.д.». «Музыканты должны делать музыку, художники должны рисовать, поэты должны писать, если они хотят быть в конечном итоге в мире с собой. Люди должны стать такими, какими они могут стать. Они должны быть верны своей природе. Эту потребность мы можем назвать самоактуализацией» [6].

Основная идея А. Маслоу заключается в том,
\end{abstract} что все мы можем самоактуализироваться. Если мы решим, что хотим этого. Абрахам Маслоу заявил, что у всех нас есть эти ресурсы внутри, и будем ли мы здоровыми или нездоровыми зависит от нас.

Сочинения Абрахама Маслоу были ориентированы, прежде всего, на коллег-психологов. И они на самом деле являются нелёгким чтением для среднего человека, и требуют много времени и терпения. Однако, для тех, кто интересуется, его книги полны занимательной и ценной информации.

Две его самые известные книги "Мотивация и личность" и “Психология бытия". Эти труды охватывают все основные положения теории А. Маслоу, в том числе иерархию потребностей, характеристику способного к самореализации человека, метамотивацию, вершинные переживания, и его собственное определение «науки психология». Они содержат тематические исследования и примеры и могут способствовать более полному пониманию теории Маслоу с его собственной точки зрения.

Рассмотрим некоторые аспекты его теории, а именно, концепцию иерархии потребностей и теорию самоактуализации.

Наши потребности заставляют нас расти и актуализироваться. Когда разговор заходит о развитии личности, А. Маслоу предлагает к рассмотрению иерархию потребностей и предполагает, что эти потребности выступают в качестве мотиваторов, чтобы заставить людей работать в направлении роста и собственного прогресса. Самые насущные потребности, способствующие выживанию, должны быть удовлетворены первыми.

Из своих наблюдений он определил, что потребности в нижней части иерархии должны быть, по меньшей мере, частично удовлетворены, прежде чем следующий уровень потребностей выйдет на поверхность. Например, человек, живущий в бедности и в крайней нужде, очень мало думает о чувстве принадлежности и самоуважении.

Потребности одного уровня могут доминировать только в какой-то момент времени. Хотя, воз- можно, следующие потребности начинают возникать, когда те только частично удовлетворены.

Цель самоактуализации состоит в том, чтобы двигаться вверх по пирамиде от низших потребностей к высшим. В этом смысл развития личности.

На рис. 1 схематически представлена концепция иерархии потребностей.

Самоактуализация, с этой точки зрения, может определяться, как предполагаемая компетентность личности удовлетворять основные потребности с тем, чтобы беспрепятственно заниматься деятельностью, являющейся сущностным смыслом её жизни, где сущностью личности выступают нестандартные, неповторимые её характеристики, индивидуальность, с актуализацией которых человек поднимается вверх по иерархии потребностей. И это способствует его личностному росту и развитию, повышает качество жизни, улучшает адаптацию, а, следовательно, личностное здоровье.

Самоактуализация была описана А. Маслоу, как способность преодолевать уровни физиологических, психологических и социальных потребностей, чтобы получить удовлетворение личных потребностей с точки зрения смысла жизни. Он заявил, что этот тип роста является линейной эскалацией удовлетворения потребностей, представленной пирамидальной иерархией. Уровни, которые он описывает, выражают эти потребности в порядке их иерархического превосходства. Это следующие потребности:

1. Физиологические потребности (голод, жажда, воздух, сон и т.п.);

2. Потребности в безопасности и защите;

3. Потребности в принадлежности и любви; эти потребности могут принимать две формы: (а) удовлетворение потребности на основе дефицита эгоистичным способом, брать вместо того, чтобы давать; и (b) потребность бескорыстной любви, основанная на росте, а не на дефиците;

4. Следующий уровень характеризуется самоуважением или потребностью в самоуважении и уважении;

5. И, наконец, заключительный этап, самоактуализация, отражает суть потребностей, состоящий в творческом саморазвитии с точки зрения своего потенциала, движение к цели и ощущению смысла жизни.

На практике можно заметить, что на приём к психологу часто приходят люди, не понимающие, чего конкретно они хотят. Суть их запроса не видна сразу даже психологу. Приходится помогать фор- 


\section{Личностный рост}

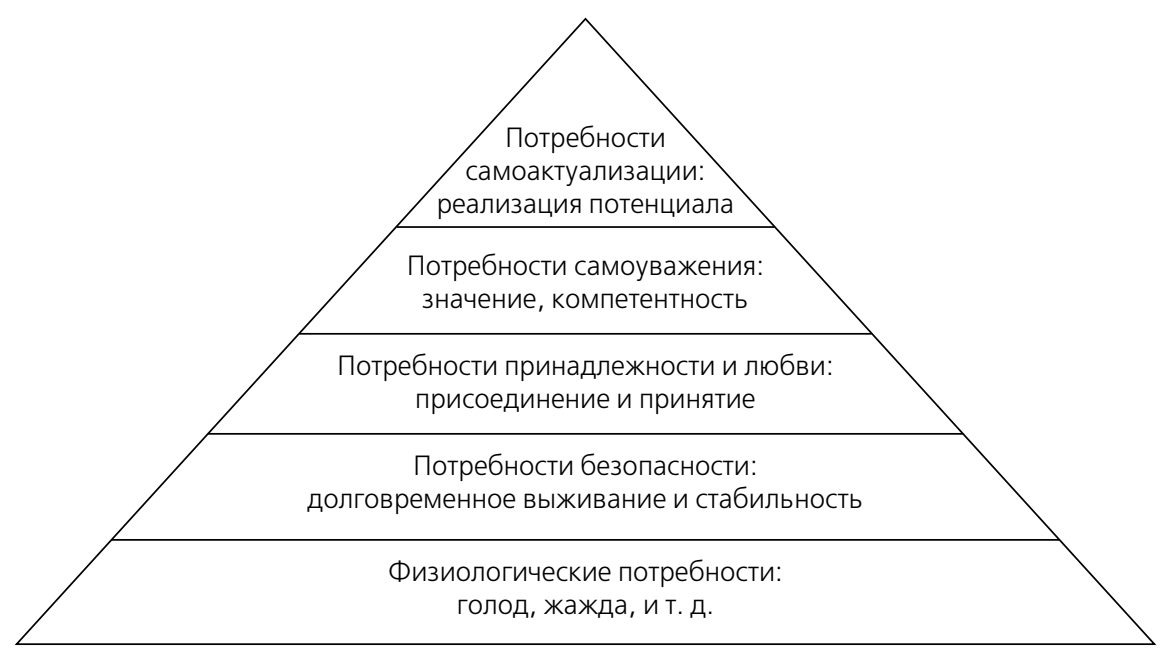

Рис. 1. Иерархия потребностей А. Маслоу

мулировать их собственные потребности и желания, так как от самих клиентов непосредственная сущность желаний совсем сокрыта. В связи с этим, мотивированные фиктивными целями, люди не получают удовлетворения от жизни. Возникающие апатия и депрессии на почве неудовлетворения потребностей и неумения расставить их в приоритетном порядке, не редко приводят людей в кабинет психолога и психотерапевта.

Таким образом, описанная А. Маслоу тенденция к самоактуализации требует большего изучения и более пристального внимания для создания научно обоснованных профилактических мероприятий, направленных на оздоровление личности. Такими мероприятиями могут стать и информационные научные и научно-популярные статьи, а также обучающие семинары. Но, главное, на чём необходимо сделать упор, это образовательная среда и подготовка квалифицированных и компетентных психологов и преподавателей, которые сами должны иметь тенденцию к саморазвитию и способность привить её студентам и клиентам.

Проследим, каким образом А. Маслоу предлагает нам актуализировать свои потенции и встать на путь развития собственной личности и обретения гармонии в жизни. В своей пирамиде потребностей он явно не указывает, как происходит их выполнение. Но утверждает, что потребности должны быть удовлетворены в приоритетном порядке, начиная с наиболее важных для жизни (витальных), и только после этого на первый план выходят потребности, связанные с личностным смыслом в жизни.

А. Маслоу дополнительно заявляет, однако, что потребности могут удовлетворяться лишь ча- стично на данный момент. Он утверждает, что такие потребности могут быть выполнены в любом порядке, учитывая, что потребности, касающиеся выживания, могут нарушать этот порядок, даже тогда, когда человек может более или менее удовлетворить экзистенциальные потребности. Кроме того столкновение с жизнью и смертью может представляться дихотомией, которую пытается решить индивидуум на данный момент жизни. Самоактуализирующийся человек, по мнению Маслоу, может найти смысл в конфронтации со смертью и увидеть диалектической контраст между жизнью и смертью, в частности. Т.е. такая личность может увидеть позитивные моменты для роста и развития в сложных жизненных ситуациях. И даже найти ресурс для нового поворота своей мировоззренческой позиции. Открытость новому, способность учиться, адекватность и конгруэнтность дают возможность такому человеку найти смысл в любой ситуации.

Например, Виктор Франкл, переживший Холокост, никогда не отказывался от поиска смысла. Это означает, что уровни низших потребностей были преодолены им ранее, и на этапе лишений, несмотря на отсутствие удовлетворения этих потребностей, он был мотивирован чем-то большим. Смысл жизни всегда индивидуален. Вслед за Ницше Франкл повторяет: «Тот, у кого есть для чего жить, может выдержать почти любое как» [11].

Такой взгляд предполагает, что индивид, имеющий возможность удовлетворять потребности низшего порядка, не будет отвлекаться от основного - от дела, которому он посвящает большую часть своей жизни. 


\section{Психология и психотехника 6(81) • 2015}

\begin{abstract}
А. Маслоу обнаружил, что самоактуализирующиеся субъекты находили также удовольствие в жизни, несмотря на тяготы, боль, печаль и разочарования. Они проявляли больше заинтересованности, меньше тревожности и меньше ощущали бесцельность существования. В то время как остальные люди лишь в редкие моменты своей жизни испытывали радость и удовольствие, самоактуализирующиеся люди, наслаждались жизнью в целом [9].
\end{abstract}

А. Маслоу объяснял это явление следующим образом. Он полагал, что люди мотивированы для поиска личных целей, и это делает их жизнь значительной и осмысленной [8]. Жизнь человека характеризуется тем, что всегда существуют желания, являющиеся сутью его потребностей. Удовлетворение же низших потребностей делает возможным осознание потребностей высшего порядка. И здесь на передний план выступают потребности самоактуализации.

Маслоу охарактеризовал самоактуализацию как потребность человека стать тем, кем он может стать. Человек, достигший этого высшего уровня, добивается полного использования своих талантов, способностей и раскрытия потенциала личности. Самоактуализироваться - значит стать тем человеком, которым мы можем стать, достичь вершины своих внутренних возможностей, выразить себя через деятельность [10]. Кроме того, жизнь на более высоком уровне потребностей означает большую биологическую эффективность, большую продолжительность жизни, уменьшение болезней, улучшение сна и аппетита, преобладание духовных ценностей и т.д. Потребности высшего порядка указывают на повышение качества жизни личности.

Более высокие уровни потребностей называют потребностями роста. Они не являются жизненно необходимыми - хотя они действительно приводят к счастью, удовлетворению, улучшению здоровья и более комфортным отношениям с окружающими. Потребности высокого уровня А. Маслоу называет метамотивациями.

Понятие метамотивации относится к поведению, на которое влияет рост потребностей и переориентация ценностей. Метамотивация часто принимает форму служения идеалам или целям. Метапотребности связаны со стремлением личности актуализировать свой потенциал. Они обогащают жизненный опыт, расширяют мировоззрение, дают возможность заниматься любимым делом, поднимают человека на более высокий уровень духовного развития.
Как показано А. Маслоу, самоактуализирующийся человек любит творческие занятия, такие как литература или поэзия и наслаждается искусством. Творчество может отражать трансцендентность с точки зрения самореализации, которая опирается на материализацию себя через опыт самопознания.

Творчество является одновременно сознательным и бессознательным процессом, как нечто преднамеренное и непреднамеренное. Искусство и признание может привести к «вершинному опыту», как описано в характеристике самоактуализирующихся личностей А. Маслоу.

Творчество объединяет дихотомии между свободной волей и детерминизмом, в том смысле, что искусство опирается на обе причины, и на свободное проявление волевой активности, как художника, так и на получателя художественного выражения. Творчество также позволяет объединить субъект и объект, для себя и других, по крайней мере, насколько сохраняется сцепление субъекта и объекта или поэта и ценителя искусства. Сознательное и бессознательное являются в некоторой степени едиными через приём художественного выражения. Творчество может находиться в пределах суть диалектической трансцендентности.

Самореализация через поэтическое выражение и приём светоотражающей коммуникации усиливают психологическое здоровье личности. Кроме того самореализация становится возможной для поэта и его аудитории, так как обе стороны получат самопознание через поэтическое выражение, будь то через процесс становления осознания смысла собственных слов или слов других людей.

Самоактуализация - это черта, которая находится на вершине в иерархии потребностей А. Маслоу. Хотя все люди способны к достижению состояния самоактуализации, мы не все достигаем его в нашей жизни. Есть только некоторые, которые смогут достигнуть этого прекрасного состояния ума. Он изучал характеристики, которые как он считал, необходимы для достижения этого состояния сознания, и пришел к некоторым неожиданным выводам.

Вершина его пирамиды потребностей подчёркивает способность индивида достичь полного раскрытия потенциала своей личности. Его список самоактуализировавшихся личностей включает следующих известных деятелей, как примеры людей, добившихся раскрытия своего потенциала: Альберт Эйнштейн, Авраам Линкольн, Томас Джефферсон, Элеонора Рузвельт. 


\section{Личностный рост}

Он предположил, что вершинный опыт определяется как момент жизни, когда мы счастливы, восторженны. Это когда мы чувствуем себя живыми и реальными. Человек занимается «сущностью», делом и не знает других чувств, таких как дефицит в чём-либо, и не задумывается о том, что другие люди думают о нём в этот конкретный момент.

Ряд исследователей, работающих с этой проблемой, обнаружили, что вершинный опыт не является результатом сознательного планирования. Эти вершинные переживания являются естественным продвижением, присущим людям искусства, например.

Маслоу выделил следующее характеристики самоактуализирующихся личностей:

- Эффективное восприятие реальности и возможность терпеть неопределённость;

- $\quad$ Принятие себя и других такими, какие они есть;

- Спонтанность в мыслях и действиях;

- Ц Центрация на проблеме (не эгоцентричны);

- Хорошее чувство юмора;

- Объективный взгляд на мир;

- $\quad$ Креативность (высоко творческие личности);

- Сопротивление окультуриванию, вне любой определённой культуры;

- Заинтересованность в благосостоянии человечества;

- $\quad$ Способность на глубокую признательность за жизненный опыт других (т.е. уважение и способность учиться у других);

- $\quad$ Способность к созданию глубоких удовлетворяющих межличностных отношений с людьми;

- Вершинный опыт.

Если индивид стремится к удовлетворению потребностей высокого уровня, это является показателем его психического здоровья. А. Маслоу считает, что удовлетворяя потребности высокого порядка, человек чувствует себя более счастливым и сама метамотивация свидетельствует о личностной зрелости.

Самоактуализация заключается в том, что, приняв решение посвятить свою жизнь духовному росту и полному раскрытию своих способностей, индивид стремится к цели и придерживается соответствующего поведения. В работу по самоактуализации входит способность выбрать достойную, требующую творческих усилий цель. Обычно личность с тенденцией к самоактуализации выбирает наиболее труднодостижимую цель.

Поскольку каждый человек уникален, самоактуализация будет отличаться для каждого человека в зависимости от его возможностей.
Взгляды А. Маслоу были подвержены жёсткой критике коллегами-психологами. Но, несмотря на это, его теория имеет много заслуг и возрождается с популярной на текущий момент позитивной психологией.

На сегодняшний день большинство зарубежных и отечественных авторов рассматривают личностный рост как необходимую составляющую на пути к самоактуализации. Теория самоактуализации является ключевым системообразующим элементом гуманистического направления в психологии. Фундаментальной для гуманистической психологии является идея о том, что осознанное стремление к максимально возможному раскрытию своего потенциала и его реализации в практической жизнедеятельности на благо общества путём самоактуализации является необходимым фактором полноценного развития человека [12].

Надо отметить что, говоря о необходимости формирования нового подхода к пониманию психики, А. Маслоу подчёркивал, что он не отвергает существующие подходы и старые школы. Самое ценное в психике, по его мнению, - её самость, её стремление к саморазвитию [14].

В настоящее время существует необходимость выявления связи исторически сложившихся гуманистических воззрений на природу человека с современным взглядом. Гуманистические психологи исходят из того, что человек вступает во взаимодействие с миром, уже будучи наделённым определённым набором качеств. Соответственно в качестве единицы анализа для учёного гуманистической направленности выступает отдельно взятая личность с присущими ей потенциями.

Рассмотрим взгляды другого знаменитого исследователя, занимавшегося проблемой личностного роста. Это один из представителей «движения за гуманизацию психологии» американский психолог Карл Роджерс.

Главный психологический смысл личностного роста, по мнению К. Роджерса, - обретение себя и своего жизненного пути, самоактуализация и развитие всех основных личностных характеристик. А взаимодействие личности с собственным внутренним миром в целом не менее, а во многих отношениях и более значимо, нежели с миром внешним. Кардинально важным для человека является также признание и уважение его внутреннего мира другими людьми [5].

К. Роджерс считает, что стремление к полной самоактуализации является врождённым для каж- 
дого из нас. В стремлении к здоровому развитию он видит преобладающую и мотивирующую силу в человеке, действующем свободно, силу, которая не ослабляется ни прошлым опытом, ни установками настоящего. Утверждение о том, что рост возможен и является главной целью организма - один из главных постулатов Роджерса.

Для К. Роджерса тенденция к самоактуализации является не просто каким-то одним побуждающим мотивом среди множества других, а неким центром, на котором сфокусированы все остальные стремления [9]. Основной закон личностного роста, по Роджерсу: если есть необходимые условия, то в человеке актуализируется процесс саморазвития, естественным следствием которого будут изменения в направлении его саморазвития и личностной зрелости. Эти изменения - их содержание, направленность, динамика - свидетельствуют о процессе личностного роста, и, кроме того, могут выступать в качестве его критериев.

При полноценной динамике этого процесса изменения затрагивают взаимоотношения личности как с внутренним миром (интраперсональность), так и с внешним миром (интерперсональность). Соответственно и критерии личностного роста должны складываться из интраперсональных и интерперсональных. Важнейшими из них являются следующие:

- интраперсональные критерии личностного роста: принятие себя, открытость внутреннему опыту переживаний, понимание себя, ответственная свобода, целостность, динамичность;

- интерперсональные критерии личностного роста: принятие других, понимание других, социализированность, творческая адаптивность.

Только движение в указанных направлениях включает процесс открытия и обретения себя. Это дает возможность человеку становиться все более свободным и ответственным, аутентичным и неповторимым, дружелюбным и открытым, сильным и творческим и, в конечном итоге, - более зрелым и способным воспринимать мир (внешний и внутренний) не как угрозу, а как мотивацию к жизни [5].

Кроме того, гуманистические авторы считают, что рост личности приводит её к социальной зрелости. Известный учёный-гуманист двадцатого столетия Э. Фромм полагал, например, что забота, ответственность, уважение и знание - это совокупность качеств зрелого человека. Австрийский психиатр, психолог и философ-гуманист и экзистенционалист В. Франкл также уделяет ответственности, свойственной зрелой личности, важное место в своей теории. Он утверждает, что духовность, свобода и ответственность - это три столпа, три экзистенциала человеческого существования.

Учёные-гуманисты считают, что личность обладает полной свободой воли. Человек осознаёт себя, осознаёт свои поступки, строит планы, занимается поиском смыслов жизни. Человек творит собственную личность и является создателем своего счастья. Внутренний мир человека в полной мере доступен только ему самому. Основу действий человека составляют субъективное восприятие и субъективные переживания. Только личный субъективный опыт, таким образом, является ключом к пониманию поведения конкретного человека.

В рамках гуманистического подхода, личность это внутренний мир человеческого «Я» как результат самоактуализации, а структура личности - это индивидуальное соотношение «реального Я» и «идеального Я», а также индивидуальный уровень развития потребностей в процессе самоактуализации.

Научное обоснование тенденции движения человека в сторону самоактуализации является огромным вкладом гуманистических психологов в научное познание как таковое. Это новый вклад в философскую мысль, в психологию как науку вообще, так и в отдельные ее ответвления. Кроме того, некоторые науки, такие как, например, медицина, могут взять себе на вооружение основные положения гуманистической парадигмы и пересмотреть свой научный взгляд на психосоматические заболевания. Это, прежде всего, касается вопросов потенциальных возможностей личности, которые можно использовать как для лечения некоторых заболеваний, так и для их профилактики.

Идеи саморазвития и самореализации являются чрезвычайно значимыми для многих концепций о человеке (А. Маслоу, К. Роджерс, Э. Фромм, К.А. Абульханова-Славская и др.).

Отечественные учёные также занимались проблемами саморазвития, личностного роста и самоактуализации, составляющими основу зрелой личности. Для отечественных психологов актуальная потребность в саморазвитии, стремление к самосовершенствованию и самоактуализации представляют огромную ценность сами по себе. Они показатель личностной зрелости и одновременно условие ее достижения. Кроме всего прочего, актуальная потребность в саморазвитии, самоактуализации - это источник долголетия человека, причем долголетия активного, и не только физического, но и социального. С выраженным стремлением 


\section{Личностный рост}

к саморазвитию связаны и профессиональные успехи личности, достижение профессионального «акме», а также профессиональное долголетие [4].

В отечественной психологии понимание самоактуализации вытекает из идей личностного саморазвития и динамической концепции личности в процессе ее деятельности. В центре этой концепции находится человек. Основные его характеристики - целостность, саморазвитие, активная деятельностная позиция.

Одним из основоположников теории саморазвития личности в процессе деятельности в отечественной психологии признан Б.Г. Ананьев. По мнению Б.Г. Ананьева, становление личности происходит наряду со становлением ее целостности, интегрированности [2]. Целостность человека проявляется в обладании целями, в осознании и в осуществлении их на практике. Развитие личности определяется жизненной направленностью, выражающейся в стержневых целях в жизни и определяющей индивидуальность и непохожесть поведения и деятельности.

А.Г. Асмолов говорит, что поведение человека может быть понято только как история поведения, а психология личности - только как история развития изменяющейся личности в изменяющемся мире [3]. Ситуации неопределённости возникают не только при наличии внутренних и появлении внешних преград в жизни человека, но и в результате постановки человеком перед самим собой сверхзадач. По каким бы причинам такая ситуация не возникла, она ставит человека перед проблемой выбора в неопределённой ситуации, что требует ориентировки личности в сложной системе смыслообразующих мотивов и личностных смыслов. Именно с этих позиций А.Г. Асмолов подходит и к изучению феноменов самореализации и самоактуализации. Он пишет, что самоактуализация личности - это самоосуществление «иных культур». В процессе самоактуализации происходит преобразование норм данной культуры, как во внешнем, так и во внутреннем мире человека.

Другой отечественный исследователь проблемы саморазвития личности К.А. Абульханова-Славская [1] считает, что самоактуализация осуществляется лишь тогда, когда у личности сформирована устойчивая Я-концепция, и она полностью осознаёт и понимает свои способности и возможности. Исходя из внутреннего мироощущения и мировосприятия, возможна и внешняя самоактуализация личности или самовыражение.
Самоактуализация как мотив рассматривается практически во всех концепциях, посвященных исследованию этого феномена. Влияние мотивационно-потребностной сферы личности на её жизнедеятельность признается всеми авторами. Однако единого понимания мотива в психологической литературе пока мы не находим. Но нечто общее существует в концепциях многих авторов.

Е.П. Ильин говорит о побудительном и целенаправленном действии мотива. Он определяет мотив как сложное психологическое интегральное образование, побуждающее человека к осознанным действиям и поступкам и служащее основанием для этих поступков [7].

По мнению большинства авторов, занимающихся данной проблематикой, мотив самоактуализации является ключевым понятием и основной движущей силой всего процесса самореализации и саморазвития личности.

Таким образом, гуманистическая ориентация в психологии - это мировоззренческая позиция, в центре которой находится идея индивидуальности человека как высшей ценности. На уровне практики - это бережное отношение к каждому конкретному человеку, проявление эмпатии, любви и уважения.

Благодаря трудам К. Роджерса, А. Маслоу и другим зарубежным и отечественным учёным гуманистического толка в научной психологии была сформулирована новая концепция человека и его природы. Она радикально отличается от господствовавших в ней ранее представлений, в соответствии с которыми человеческая природа изначально и по своему существу несовершенна. Суть этой концепции - позитивная природа человека. Человек от рождения является носителем позитивных сил и возможностей, которые он может и желает актуализировать.

Важнейшим вкладом в гуманизацию психологии и общества в целом является научное открытие К. Роджерса: необходимые и достаточные условия гуманизации любых межличностных отношений, обеспечивающие конструктивные личностные изменения - это безоценочное позитивное принятие другого человека, эмпатия и конгруэнтность в общении с ним. Кроме того, постулирование гуманистически направленными психологами и философами тенденции к раскрытию своего личностного потенциала и применению всех своих сущностных сил может быть использовано в социологии, политологии, психологии, психиатрии, конфликтологии и многих других областях научной и общественной деятельности. 


\section{Психология и психотехника 6(81) • 2015}

Также необходимо отметить, что в гуманистической психологии личностное развитие самого психолога становится непременным условием познания другого человека, условием развивающегося взаимодействия с ним. Вот почему можно сказать, что гуманистические воззрения в психологии намечают принципиально иной путь развития психологической науки - путь, ведущий к познанию не абстрактного и искусственно сконструированного человека, а реального и подлинного, самоактуализирующегося [6].

Таким образом, изучение личностного роста и самоактуализации личности является одной из ведущих задач психологи. Исследования в области психологии, имеющие своим предметом рассмотрения тенденцию к самоактуализации личности, раскрытию своего потенциала и самоосуществлению, являются ключевыми для гуманистического направления научного психологического сообщества и их актуальность для современной науки не вызывает сомнений. Влияние подобных исследований на научное знание в целом неоспоримо. Знание своих возможностей, применение талантов и прочих способностей на благо общества делает человека счастливым, а общество богатым и духовно развитым. Такое общество менее конфликтно и более здорово. Наука, культура и отдельно взятая личность функционируют, дополняя друг друга. Самоактуализация личности способствует оздоровлению общества. Необходимость профилактической работы в целях оздоровления личности, информировании студентов, будущих и настоящих профессионалов, психологов и педагогов о значимости саморазвития для собственного здоровья и счастья, и, как следствие, здоровья общества, является актуальной проблемой современности.

\section{Список литературы:}

1. Абульханова-Славская К.А. Стратегия жизни. М.: Мысль, 1991. 299 с.

2. Ананьев Б.Г. Человек как предмет познания. СПб.: Питер, 2000. 288 с.

3. Асмолов А.Г. Психология личности. М.: Изд-во МГУ, 1990. 367 с.

4. Бордовская Н.В., Реан А.А. Педагогика. СПб., 2000304 с.

5. Братченко С.Л., Миронова М.Р. Личностный рост и его критерии. Психологические проблемы самореализации личности. СПб., 1997.

6. Догадова Е.М. Философский смысл гуманизации межличностных отношений: Дис. ... канд. филос. наук. Чебоксары, 2007.

7. Ильин Е.П. Психология индивидуальных различий. СПб.: Питер, 2004. 701 с.

8. Маслоу А. Новые измерения человеческой природы. М.: Речь, 2001. 417 с.

9. Маслоу А. Мотивация и личность. СПб.: Евразия, 1999. 478 с.

10. Фрейджер Р., Фейдимен Д. Теории личности и личностный рост. М., 2002. 690 с.

11. Франкл В. Человек в поисках смысла: введение в логотерапию // Франкл В. Доктор и душа. СПб.: Ювента, 1997. С. 13-152.

12. Хьелл Л., Зиглер Д. Теории личности. Основные положения, исследования и применение. СПб.: Питер Пресс, 1997.

13. Ященко Е.Ф. Особенности самоактуализации студентов с разной профессиональной направленностью // Психологический журнал. 2006. № 03. Т. 27. С. 31-41.

14. Ярошевский М. История психологии: от античности до середины XX в. М.: Академия, 1996. 409 с.

\section{References (transliteration):}

1. Abul'khanova-Slavskaya K.A. Strategiya zhizni. M.: Mysl', 1991. 299 s.

2. Anan'ev B.G. Chelovek kak predmet poznaniya. SPb.: Piter, 2000. $288 \mathrm{~s}$.

3. Asmolov A.G. Psikhologiya lichnosti. M.: Izd-vo MGU, 1990. 367 s.

4. Bordovskaya N.V., Rean A.A. Pedagogika. SPb., 2000. 304 s.

5. Bratchenko S.L., Mironova M.R. Lichnostnyi rost i ego kriterii. Psikhologicheskie problemy samorealizatsii lichnosti. SPb., 1997.

6. Dogadova E.M. Filosofskii smysl gumanizatsii mezhlichnostnykh otnoshenii: Dis. ... kand. filos. nauk. Cheboksary, 2007.

7. Il'in E.P. Psikhologiya individual'nykh razlichii. SPb.: Piter, 2004. $701 \mathrm{s.}$

8. Maslou A. Novye izmereniya chelovecheskoi prirody. M.: Rech', 2001. 417 s.

9. Maslou A. Motivatsiya i lichnost'. SPb.: Evraziya, 1999. $478 \mathrm{~s}$.

10. Freidzher R., Feidimen D. Teorii lichnosti i lichnostnyi rost. M., 2002. $690 \mathrm{s.}$

11. Frankl V. Chelovek v poiskakh smysla: vvedenie v logoterapiyu // Frankl V. Doktor i dusha. SPb.: Yuventa, 1997. S. 13-152.

12. Kh'ell L., Zigler D. Teorii lichnosti. Osnovnye polozheniya, issledovaniya i primenenie. SPb.: Piter Press, 1997.

13. Yashchenko E.F. Osobennosti samoaktualizatsii studentov s raznoi professional'noi napravlennost'yu // Psikhologicheskii zhurnal. 2006. № 03. T. 27. S. 31-41.

14. Yaroshevskii M. Istoriya psikhologii: ot antichnosti do serediny XX v. M.: Akademiya, 1996. 409 s. 